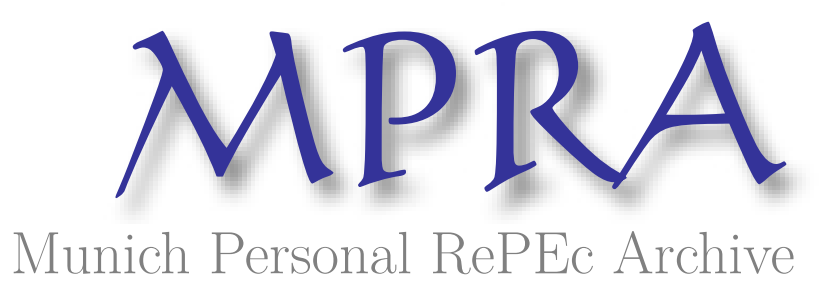

\title{
Quantitative Analysis of Dynamic Inconsistencies in Infrastructure Planning: An example of coastal levee improvement
}

Kono, Tatsuhito and Kitamura, Naoki and Yamasaki, Kiyoshi and Iwakami, Kazuki

Tohoku University, Value Management Institute, Inc.

2016

Online at https://mpra.ub.uni-muenchen.de/107920/

MPRA Paper No. 107920, posted 25 May 2021 01:30 UTC 


\title{
Quantitative Analysis of Dynamic Inconsistencies in Infrastructure Planning:
}

\section{An example of coastal levee improvement}

\author{
KONO Tatsuhito \\ Tohoku University, e-mail: kono@plan.civil.tohoku.ac.jp \\ KITAMURA Naoki \\ Tohoku University, e-mail: kitamura@se.is.tohoku.ac.jp \\ YAMASAKI Kiyoshi \\ Value Management Institute, Inc., e-mail: kiyoshi_yamasaki@vmi.co.jp \\ IWAKAMI Kazuki \\ Value Management Institute, Inc. e-mail: kazuki_iwakami@vmi.co.jp
}

\begin{abstract}
Cost-benefit analysis (CBA) is considered as an effective means to avoid the government's failures of public projects. However, once CBA becomes mandatory and residents expect a public project to be established based upon it, there is the potential for a dynamic inconsistency problem to arise, where dynamic inconsistency is defined as a difference in the optimal policy between before and after a timing. Taking as an example the coastal levee improvement policy in the city of Rikuzentakata in Japan, the present study clarifies the mechanism behind the dynamic inconsistency problem that is attributable to mandatory CBA and also discusses quantitatively the influence of the dynamic inconsistency problem on social welfare. In addition, through examining the quantitative result, we indicate that, in the projects where the improvement cost increases gradually with the scale, the inefficiency of the dynamic inconsistency problem is incurred on a larger scale.
\end{abstract}

Keywords: Dynamic (or time) inconsistency problem, Cost-benefit analysis, Public investment.

JEL classification: R14, R53, R54 


\section{Introduction}

Cost-benefit analysis (CBA) for public investments has become mandatory in many countries. In these countries, CBA manuals have been put in place for each type of project. CBA is considered as an effective means to avoid implementing futile public projects. However, once CBA becomes mandatory, residents can behave strategically with the expectation that a public project is established based upon it, which has the potential to result in failing to achieve the social optimal welfare, and this is known as the so-called dynamic inconsistency problem. ${ }^{1}$

Dynamic inconsistency problem is described in the first part of the abstract of Kydland and Prescott (1977) as "Even if there is an agreed-upon, fixed social objective function and policymakers know the timing and magnitude of the effects of their actions, discretionary policy, namely, the selection of that decision which is best, given the current situation and a correct evaluation of the end-of-period position, does not result in the social objective function being maximized."

One example of this problem, which is indicated by Kydland and Prescott (1977), is "the problem of constructing levees because many people have migrated to the area prone to flooding, where land prices are low." In this example, if many people migrate to such areas with the expectation that levees will be constructed, social optimal welfare cannot be achieved because costly levees are eventually constructed. This migration can take place when many residents migrate together through the coordination of developers. Mandatory CBA underpins the residents' rational expectation that levees will be constructed and thus accelerates the occurrence of the dynamic inconsistency problem.

An inconsistency arises in which the CBA-based optimal policy changes if the

${ }^{1}$ The mechanism of the dynamic inconsistency problem can be roughly categorized into two cases: one where the optimal dynamic policy at a certain time ceases to become optimal only with the lapse of time; and the other where, in a Stackelberg game for two or more players, the sub-game perfect solution differs from the social optimal solution. The present study targets the latter. The dynamic inconsistency problem is also called the time inconsistency problem. 
residential distribution changes due to the strategic migration of residents. Indeed, since public investment is evaluated based on residents' actions (i.e., revealed preference data) in CBA, what is determined as the optimal policy differs before and after the residents' actions. The CBA is based on residents' behavior ${ }^{2}$ because the government cannot directly observe the change in the utility level. In other words, information on residents' preference is asymmetric between residents and the government.

The fact that the optimal policy differs before and after the dynamic timing (in this case, the timing of residents' actions) is known as the dynamic (or time) inconsistency problem. The general structure that is the cause of this problem was indicated by Kydland and Prescott (1977). "Constructing levees because residents have migrated to the area prone to flooding" mentioned above is one of several examples of the dynamic inconsistency problem indicated in their paper. However, no specific modeling or analysis, including a CBA of levees, of this example has yet been made.

The dynamic inconsistency problem is formulated as a Stackelberg game between the policymaker and the private sector and has been studied by many papers concerning monetary policies (e.g., Barro and Gordon (1983), Calvo (1978a), Calvo (1978b)). Studies have been also conducted concerning various public policies. ${ }^{3}$ However, an analysis of the dynamic inconsistency problem related to CBA is limited to Kono and Notoya (2012). They showed the mechanism of the dynamic inconsistency problem and the sufficient conditions under which the problem arises for cases where transportation service is a fixed

${ }^{2}$ If the utility level could be measured directly, the policymaking authorities would be able to determine the best investment level and commit to the optimal policy. If they could commit to the optimal policy, residents' strategic migration could be prevented, and no dynamic inconsistency problem would arise. However, the policy of controlling the residential population itself does not generally exist and only land use regulation is in place. Hence, even if an optimal residential population can be calculated, it is generally difficult for the policymaking authorities to limit the population.

3 Included in analyses other than for monetary policy are those by Boadway et al. (1996) for educational investment, Glazer (2000) for traffic toll, Richer (1995) for urban development, Kornai (1979), Qian and Roland (1998), and Akai and Sato (2008) for soft budget problems in local government finance, Bassetto (2008) and Mitsui and Sato (2001) for the issue of public-goods cost burden sharing among generations. 
capital service (e.g., highway investment) and a variable flow service (e.g., bus services), respectively. However, their analysis is limited to a qualitative one, and the degree of inefficiency is not analyzed. Even in cases that do not involve CBA, the number of quantitative analyses of the dynamic inconsistency problem is extremely limited (Kiuchi, $2005) .^{4}$

The present study makes an analysis using the example of coastal levee improvement, with an eye to showing the degree of inefficiency of the dynamic inconsistency problem brought about by the use of CBA. Coastal levee improvement is taken as an example here because the mechanism is the same as the example of levees used by Kydland and Prescott (1977), and, in addition, a similar dynamic inconsistency problem can arise in practice somewhere in the area devastated by tsunami. Through examining a quantitative relationship between the degree of inefficiency and the nature of the infrastructure, we examine what kinds of infrastructure improvements are necessary to take the inefficiency of the dynamic inconsistency problem related to CBA into consideration.

Our model incorporates the effect of coastal levee improvement into a computable urban economic (CUE) model developed in Ueda et al. (2013). The CUE model is a spatial version of computable general equilibrium (CGE) models. Spatial CGE models have been already used for evaluating various policies (e.g., Anas (2013), Anas and Hiramatsu (2011), Bröcker (1998), Echenique (1994) and Kii and Doi (2005)). As Anas (2013) describes, CGE models are structural as opposed to reduced-form economic models. Structural models can be based solidly in microeconomic theory - since they do not require a departure from the underlying fundamental functional forms of demand and supply — and therefore they are free of the commonly known pitfalls of reduced-form models. Accordingly, CGE models can be used for rigorous welfare analysis. Similarly, Echenique (1994) also

\footnotetext{
${ }^{4}$ Referring to the reason why only a few quantitative analyses are available, Kiuchi (2005) states that it is difficult to observe variables of discipline and incentive, in many cases. Examples of quantitative analyses are Persson and Tabellini (2004), Klein et al. (2008), and Pettersson-Lidbom (2010).
} 
denotes that as one advantage of CGE models, the market concept is that the system produces a set of prices and quantities which can form the basis of a system of economic evaluation. Rikuzentakata (see Fig. 1 for the location), which suffered from the devastating tsunami in the wake of the Great East Japan Earthquake, is selected as the study area. The parameters of our CUE model are calibrated using actual data.
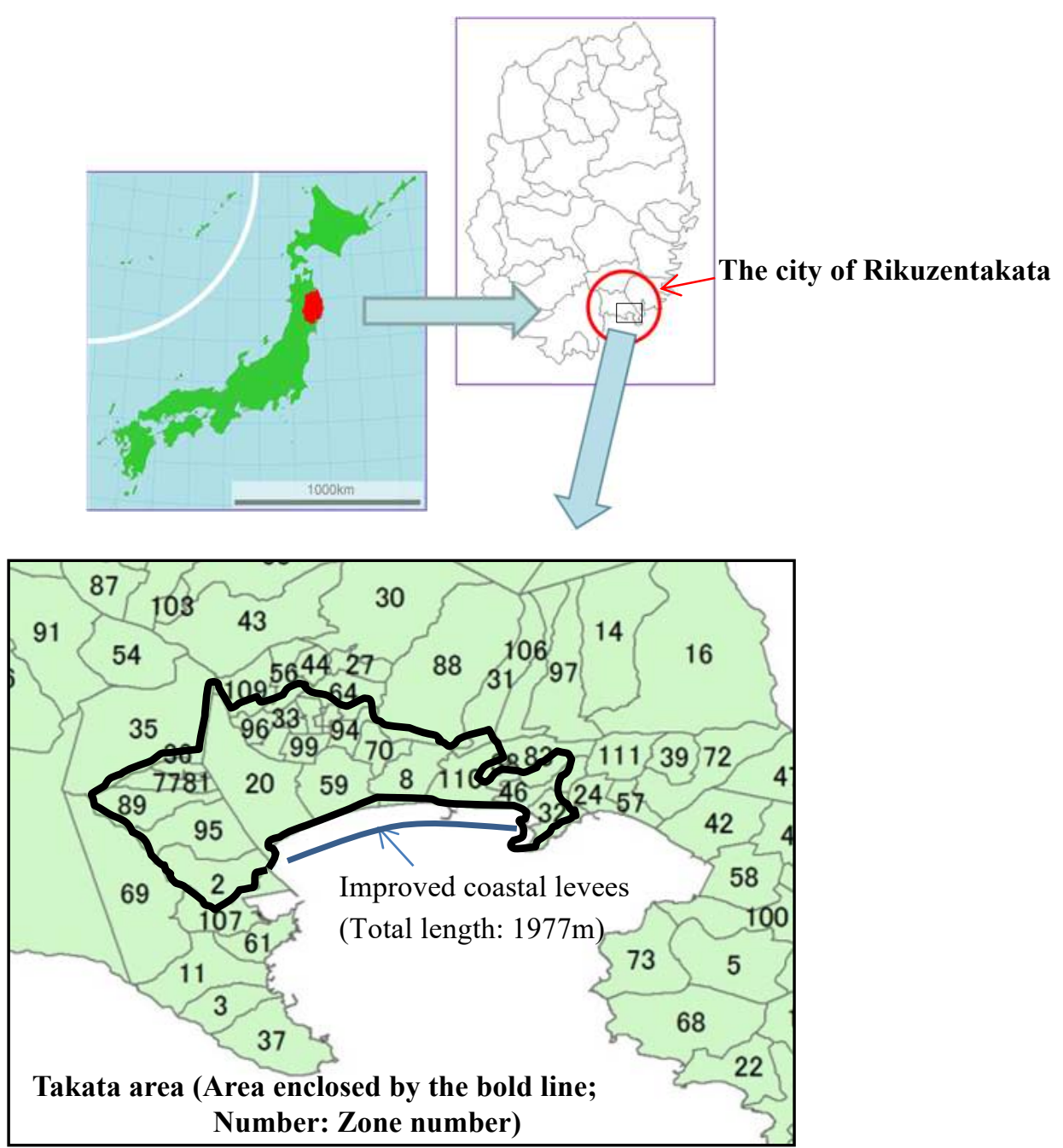

Figure 1 Location of Rikuzentakata and the improved levees

Simulation is conducted for the following two cases. 
Case 1: Social optimal case where the social welfare is maximized, and

Case 2: Dynamic inconsistency case where the government determines the coastal levee height through CBA after residents have strategically migrated.

In Case 1, the coastal levee height is determined to maximize the social surplus in the CUE model with the coastal levee height as a given condition. In Case 2, the coastal levee height is determined from the Stackelberg game, where residents are the leader and the government that determines the levee height is the follower.

The present study aims to analyze quantitatively the mechanism behind the dynamic inconsistency problem in infrastructure improvement but does not intend to evaluate the actual restoration plan after the 2011 Tsunami. As a matter of fact, the restoration plan being developed in Rikuzentakata is different from the land use plan before the earthquake. The current plan is to locate parks and industrial zones in the previous urban zone, to where the residential area used to extend before the earthquake. However, a dynamic inconsistency problem can occur in almost the same mechanism, meaning that the planned scale and daytime population can be set larger even in the parks and industrial zones to obtain more advantageous CBA results.

Consequently, in terms of the scope of application of our results to the actual restoration plan, the qualitative mechanism can be considered to occur potentially as a problem in the actual restoration plan. Next, using the quantitative results, the coastal levee height before the earthquake can be evaluated ex post facto, and the validity of the coastal levees with a height of $12.5 \mathrm{~m}$ currently planned can be examined. While these are not our main subjects, the results for these subjects will be shown where necessary.

\section{Computable urban economic model: Rikuzentakata Model}

The model covers Rikuzentakata and comprises 111 zones by town-chome, with the computable urban economic (CUE) model by Ueda et al. (2013) used as a basis. Aside from the government, there are two agents: residents and absentee land owners. To reflect some 
heterogeneities, heterogeneities in incomes and preference are modeled for two age groups: the elderly and the rest. Residents select their residential locations. The migration cost is assumed to be zero to obtain long-term equilibrium. Because of such free migration, a spatial utility equilibrium holds. Land is owned by absentee landlords outside Rikuzentakata.

\subsection{The CUE model}

Residents consume personal trips $x_{i}^{m}$ (number of trips), land area $l_{i}^{m}$ (consumption on residential land), and composite goods $Z_{i}^{m}$. They maximize their utilities subject to their income constraints. Technically, the utility function is specified to be quasi-linear for simplicity and can be expressed using Eq. (1). Equation (2) shows the income constraint.

$$
\begin{aligned}
& V\left(q_{i}, r_{i}, I_{i}^{m}\right)=\max \left[\alpha_{x}^{m} \ln x_{i}^{m}+\alpha_{l}^{m} \ln l_{i}^{m}+Z_{i}^{m}+\tau_{i}^{m}\right] \\
& \text { s.t. } \quad Z_{i}^{m}+q_{i} x_{i}^{m}+r_{i} l_{i}^{m}=I_{i}^{m}-D_{i}^{m} \quad\left(\text { where, } I_{i}^{m} \equiv w\left(t^{m}-s_{i}^{m}\right)\right)
\end{aligned}
$$

where $i$ : Subscript showing the zone (111zones), $m$ : Superscript showing the age group (the non-elderly and the elderly), $q_{i}$ : Personal trip cost, $r_{i}$ : Residential land rent, $I_{i}^{m}$ : Income per capita, $\alpha_{x}^{m}, \alpha_{l}^{m}$ : Parameters, $w$ : Time value (=wage rate), $t^{m}$ : Binding hour, $s_{i}^{m}$ : Commuting time, $D_{i}^{m}$ : Expected value of tsunami damage per year by zone, and $\tau_{i}^{m}$ : Degree of attraction specific to the zone (simple sum of the fixed value $\bar{\tau}_{i}$ and the random variable $\varepsilon_{i}$ different among individuals).

In principle, the risk premium should be also taken into account using an expected utility function and a strictly concave utility function. Due to the constraint on the data, however, it is impossible to calibrate a complex model. Hence, the present study uses a quasi-linear utility function, which leads to no risk premium, as a primary approximation. Consequently, the influence of tsunami damage can be expressed by the expected value $D_{i}^{m}$, which is subtracted from the income. This can be interpreted to mean that residents are preparing for the damage by accumulating the expected value of damage suffered annually. This can also be interpreted as the case where full insurance is available and residents have taken out insurance. 
Solving Eqs. (1) and (2) for utility maximization yields Eqs. (3) and (4).

$$
\begin{aligned}
& x_{i}^{m}=\alpha_{x}^{m} / q_{i} \quad \text { and } \quad l_{i}^{m}=\alpha_{l}^{m} / r_{i} \\
& V_{i}^{m}=I_{i}^{m}-D_{i}^{m}-\alpha_{x}^{m} \ln q_{i}-\alpha_{l}^{m} \ln r_{i}-\alpha_{x}^{m}-\alpha_{l}^{m}+\tau_{i}^{m}
\end{aligned}
$$

According to Eqs. (3), parameters $\alpha_{x}^{m}$ and $\alpha_{l}^{m}$ can be expressed using the annual amount of consumption on traffic and land as $\alpha_{x}^{m}=q_{i} x_{i}^{m}$ and $\alpha_{l}^{m}=l_{i}^{m} r_{i}$, respectively.

The residents in age group $m$ change their location to the zone where the utility level $V_{i}^{m}$ is higher. Assuming that the random variable $\varepsilon_{i}$ follows the Gumbel distribution (average: zero, variance: $\left.\pi^{2} / 6\left(\theta^{m}\right)^{2}\right)$, the location selection behavior can be expressed by a logit model. The zone population $N_{i}^{m}$ is calculated by multiplying the total population of the zone by age group $N_{T}^{m}$ and the location selection probability $P_{i}^{m}$ together.

$$
\begin{aligned}
& P_{i}^{m}=\frac{\exp \theta^{m}\left(V_{i}^{m}+\bar{\tau}_{i}^{m}\right)}{\sum_{i} \exp \theta^{m}\left(V_{i}^{m}+\bar{\tau}_{i}^{m}\right)} \quad i \in\{1, \cdots, 111\} \\
& N_{i}^{m}=P_{i}^{m} \cdot N_{T}^{m} \quad i \in\{1, \cdots, 111\}
\end{aligned}
$$

where $\theta^{m}$ is the logit parameter (normalized to 1) of the location selection model.

The total land demand $L_{i}^{m} \quad$ can be expressed by multiplying the consumption on land area per person and the number of residents in each location together as shown by eq. (7).

$$
L_{i}^{m}=l_{i}^{m} \cdot N_{i}^{m} \quad i \in\{1, \cdots, 111\}
$$

Appendix shows the estimated time value, income, land and traffic parameters, and commuting time to be used in our model, together with the respective sources of data used for calibration. The data and the development of trip data for calibration is shown in Supplement on the authors' website. The employment locations, or commuting destinations, are supposed to be fixed, and the actual data before the Great East Japan Earthquake are used for the number of employees by zone.

A land supply function for residential use is specified as (8) and the parameters are estimated to create the land supply function using actual data ${ }^{10}$ (see Appendix).

${ }^{10}$ The regression results are described in Appendix. The land use data creation is explained in the first 


$$
y_{i}=A\left(r_{i}\right)^{\sigma} Y_{i} \cdot \Delta_{i}
$$

where $y_{i}$ : Residential land supply area, $Y_{i}$ : Maximum residential land area that can be supplied, $A$ and $\sigma$ : Parameter, and $\Delta_{i}$ : the constant term by zone $i$.

The equilibrium condition for the land market can be expressed by Eq. (9), and the constraint on the population is expressed by Eq. (10).

$$
\begin{aligned}
& y_{i}=\sum_{m} L_{i}^{m} \quad i \in\{1, \cdots, 111\} \\
& \sum_{i} N_{i}^{m}=N_{T}^{m} \quad m \in\{1,2\}
\end{aligned}
$$

\subsection{Model of coastal levee and tsunami risk}

As the improved coastal levee height increases, the annual amount of tsunami damage decreases. To calculate the annual damage $D_{i}^{m}$, initially set the flood water depth by tsunami height by levee height for each zone and subsequently consider the probability of occurrence of a tsunami by the tsunami run-up height to calculate the tsunami damage

Here, the flood water depth means the height from the ground surface to the water surface in the flooded area and the run-up height means the altitude reached by the tsunami that has landed (see Otaru City Website for a graphical explanation). The method used to set the flood water depth is as follows: Set the flood water depth by zone by using the data for the Earthquake and Tsunami Simulation and Damage Estimation Survey for Rikuzentakata (Iwate Prefecture, 2003)) over the zones by town-chome for the Takata $\operatorname{area}^{13}$ (see Fig. 1) in the central part of Rikuzentakata. The tsunami simulation supposed that the run-up height of an expected big earthquake was $10.2 \mathrm{~m}$. We assume that the run-up height based in their simulation is $10 \mathrm{~m}$.

Set the flood water depth $\Lambda_{i}(K, \Phi)$ by zone for each coastal levee height. Initially, as Case i), for a tsunami with a run-up height $\Phi$ of $10 \mathrm{~m}$ or less, if the run-up height exceeds

author's web site.

13 Term is defined for the purpose of the present study and the collective designation of the zones affected by the coastal levee improvement. A map is shown in Fig. 1. 
the improved coastal levee height $K$, the flood water depth $\Lambda_{i}(K, \Phi)$ will be the same as the estimated flood water depth $\Omega_{i}$ in the tsunami simulation (2003) as shown in Eq. (11). Subsequently, as Case ii), for a tsunami run-up height $\Phi$ exceeding a run-up height of $10 \mathrm{~m}$ set in the tsunami simulation (2003), if the run-up height exceeds the improved coastal levee height $K$, the value obtained by adding the portion in excess of $10 \mathrm{~m}$ to the estimated flood water depth $\Omega_{i}$ is set as the flood water depth as shown in Eq. (12). If the improved coastal levee height $K$ is higher than the run-up height $\Phi$, the flood water depth in all zones will be zero as shown in Eq. (13).

i) Run-up height $\Phi \leqq 10 m$ and Run-up height $\Phi>$ Coastal levee height $K$

$$
\Lambda_{i}(K, \Phi)=\Omega_{i}
$$

ii) Run-up height $\Phi>10 m$ and Run-up height $\Phi>$ Coastal levee height $K$

$$
\Lambda_{i}(K, \Phi)=\Omega_{i}+(\Phi-10)
$$

iii) Coastal levee height $K \geqq$ Run-up height $\Phi$

$$
\Lambda_{i}(K, \Phi)=0 .
$$

Subsequently, formulate the probability of occurrence of a tsunami $T(\Phi)$ by run-up height $\Phi$ per year. The data of the run-up heights of the past tsunamis to the Sanriku district were mainly ${ }^{15}$ extracted from the tsunami observation data (for a period of 400 years from 1611 to 2011) summarized on the website of the National Geographical Data Center of the National Oceanic and Atmospheric Administration (NOAA).

To estimate the predicted distribution in the future based on these actual data, with an assumption that tsunami with a height within $2 \mathrm{~m}$ of that of the actual tsunami would occur with the same probability, the frequency of tsunami arrival by actual run-up height $\Phi$ was

\footnotetext{
15 For large-scale earthquakes, namely, the Great East Japan Earthquake (15m), the Chilean Earthquake $(6 \mathrm{~m})$, the Showa-Sanriku Earthquake $(6 \mathrm{~m})$, the Meiji-Sanriku Earthquake (10m), and the Keicho Sanriku Earthquake $(20 \mathrm{~m})$, the data in the study area were individually investigated, and the values obtained were used. The NOAA data are for the whole Sanriku district but not for the study area, or Rikuzentakata. Hence, only for those large-scale tsunamis, the data of Rikuzentakata or Tarocho near Rikuzentakata were used.
} 
evenly allocated within the range of $\pm 2 \mathrm{~m}$ from the run-up height actually observed. ${ }^{16}$ When the data is divided by 400 (years), $T(\Phi)$ by run-up height $\Phi$ per year can be obtained as in Figure 2 (a).

Using the above settings, calculate the annual amount of damage $D_{i}(K)$. Limit the possible tsunami damage to the residents to only two items, 1) damage to their house and 2) their death. Initially, calculate 1) the deduction caused by the damage to their house. Set the cost of houses to $¥ 20$ million per house, the average number of people per household in Rikuzentakata to 3.2 (2005 national census), and the social discount rate to $4 \%$. Divide the value of their house at 20 million yen by the average number of people per household of 3.2 to determine the amount of damage to their house in the event of a flood. Multiply this amount by the probability of occurrence of a tsunami $T(\Phi)$ and add each amount obtained to determine the annual deduction per person $D_{i}^{\text {Comp }}(K)$ in the zone defined as completely destroyed $\left(\Lambda_{i}(K, \Phi) \geq 2\right)$. The annual deduction per person $D_{i}^{\text {Half }}(K)$ in the zone defined as half destroyed $\left(0<\Lambda_{i}(K, \Phi)<2\right)$ will be half of the above.

$$
\begin{aligned}
& D_{i}^{\text {Comp }}(K)=\left\{\sum_{\Phi=1}^{22}(2000 / 3.2) T_{i}(\Phi): \Lambda_{i}(K, \Phi) \geq 2\right\} \\
& D_{i}^{\text {Half }}(K)=\left\{\sum_{\Phi=1}^{22}(1000 / 3.2) T_{i}(\Phi): 0<\Lambda_{i}(K, \Phi)<2\right\}
\end{aligned}
$$

Next, calculate 2) the annual amount of damage caused by the risk of death. For the risk of death, we use 1,554 people $/ 24,709$ people $=6.29 \%$ in the case of the Great East Japan Earthquake as the tsunami fatality ratio $R$. Use 260 million (yen/person) ${ }^{18}$ estimated by the Cabinet Office (2007) for the value of statistical life. Multiply the tsunami fatality rate $(R)$ by the value of statistical life $(L)$ to determine the amount of damage to stock for the risk of death in the event of a flood. Multiply this amount by the probability of

\footnotetext{
${ }^{16}$ For tsunami less than $3 \mathrm{~m}$ in height, actual data were used. As shown in the subsequent analysis, the optimal coastal levee height is $10 \mathrm{~m}$. Since the optimal height is determined based on a comparison of the marginal benefit and the marginal cost, the way of allocating low tsunami has no influence at all on the determination of the optimal height as long as the expected value for damage does not change.

18 The average pecuniary income loss ( $¥ 33$ million) was added to the death loss ( $¥ 226$ million). This estimation is for an average person, and it might be high for the elderly people but it might be short for non-elderly.
} 
occurrence of a tsunami by the run-up height $T(\Phi)$ to determine the annual deduction per person $D_{i}^{\text {Death }}$ in the zone.

$$
D_{i}^{\text {Death }}(K)=\left\{(R \times L) T_{i}(\Phi): \Lambda_{i}(K, \Phi)>0\right\}
$$

Based on the above, the annual total amount of damage by zone $D_{i}(K)$ is obtained by adding the annual amount of damage caused by damage to houses and the annual amount of damage due to the calculated risk of death.

$$
D_{i}(K)=D_{i}^{\text {Comp }}(K)+D_{i}^{\text {Half }}(K)+D_{i}^{\text {Death }}(K)
$$

\subsection{Definition of the gross social welfare}

The improvement of levees affects residents and landowners. Accordingly, the gross social welfare is obtained from the sum of the welfare of the residents and the welfare of the absent landowners. Gross welfare means the welfare before the coastal levee cost is deducted from the social welfare. Since the welfare of the residents is expressed by the log-sum of the residents' indirect utility in all 111 zones, the gross social welfare ${ }^{19}$ is .

$$
W=\sum_{m} N_{T}^{m} \operatorname{Exp}\left\{\max _{i}\left(V_{i}^{m}+\tau_{i}\right)\right\}+\sum_{i=1}^{111} r_{i} y_{i}=\sum_{m} N_{T}^{m} \ln \sum_{i=1}^{111} \exp \left(V_{i}^{m}\right)+\sum_{i=1}^{111} r_{i} y_{i}
$$

where the first term expresses the sum of residents' utility and the second term is the total land rent revenue for absentee landowners. To compare the gross social welfare with the coastal levee improvement cost, which is a stock variable, obtain the benefit through converting into a present value using a social discount rate of $4 \%$.

\subsection{Calculation of the coastal levee improvement cost}

\footnotetext{
19 Since a flexible residential land supply function is taken into consideration, an opportunity cost concerning the residential land supply is incurred. This opportunity cost is composed of, for example, the cost of cutting down trees to prepare the land for residential use and the income from alternative use such as agriculture. In the latter case, the rental income from agricultural land merely changes to rental income from residential land, and thus it is not necessary to reduce any income for the absent landowner. However, this ratio is unknown. Hence, in the social welfare function in the present study, most of the opportunity cost was considered to be income from alternative use (e.g., income from agricultural land rent), and this opportunity cost was not deducted. Since the income from land rent is considerably less significant than utility (see Table 2 or Figure 3), neither consideration nor ignorance of the amount of this opportunity cost has any significant influence on the results.
} 
Calculate the coastal levee improvement cost by height using the regression analysis ${ }^{22}$ based on past coastal levee improvement costs for Iwate Prefecture (1969) and the data of the coastal levee improvement cost estimated by Iwate Prefecture. The construction cost deflator is used to convert the nominal cost into the real cost. The cost function is shown by Eq. (20) and it is regressed on the actual data (see Appendix). The coastal levees to be discussed in the present study are those with a total length of $1,977 \mathrm{~m}$ planned to be developed along the Takata area coast (see the blue line in Figure 1).

$$
C(K) / 1977=\gamma \exp (\phi \cdot K)
$$

where $C(K)$ : Improvement cost by improved coastal levee height $K, \gamma$ and $\theta$ : Parameters. The parameters are estimated with real costs (see Appnedix).

\subsection{Formation of the standard}

Calculate the risk $D_{i}(K=6)$ for a coastal levee height of $6 \mathrm{~m}$ above T.P., ${ }^{23}$ the same as that before the Great East Japan Earthquake, and calculate the equilibrium of the model to obtain the degree of each zone's own attraction $\bar{\tau}_{i}$ with the population density of each zone maintained identical to that before the earthquake. The equilibrium of this model with a coastal levee height of $6 \mathrm{~m}$ is defined as the "standard".

\section{Simulation}

The simulation process and results are shown in section 3.1 and 3.2, respectively. Discussion on these results is in Section 3.3.

\subsection{Simulation for each of the two cases}

We demonstrate dynamic inconsistency problem of improvement in coastal levee height. According to the definition of Kydland and Prescott, "dynamic inconsistency" in our model is defined as

${ }^{22}$ The data used for the regression analysis and the statistical results are shown in Appendix.

23 The actual levee height before the Great East Japan Earthquake is $5.5 \mathrm{~m}$. In the present study, however, calculation is made in $1 \mathrm{~m}$ increments of the coastal levee height, and the levee height before the earthquake is assumed to be $6 \mathrm{~m}$. This approximation does not affect the simulation results. 
Definition: The height of the coastal levee $K$ is dynamically inconsistent if the optimal height $K$ maximizes the social welfare function $W$ and if the optimal height $K$ is not equal to that determined given a strategic migration decision.

The current situation has this dynamic inconsistency problem. To quantitatively analyze the level of dynamic inconsistency, we calculate two cases: first one is the social optimal case and the second one is a dynamic inconsistency case.

In Social optimal case, use the CUE model developed in Section 2 and obtain the coastal levee height that maximizes the social welfare.

In Dynamic inconsistency case, the coastal levees are improved to ones of optimal height based on the residential population (or the planned population announced by the developers). Divide the area into two types of zones: the Takata area (see Fig. 1), where the flood damage level varies depending on the coastal levees; and other zones. Subsequently, set the population of the Takata area to 1.0 to 2.0 times that before the earthquake (with the population of other zones set to the one obtained by subtracting the population of the Takata area from the total population of Rikuzentakata) and determine the coastal levee height corresponding to each population using CBA.

Here, obtain the benefit of the coastal levees as the "amount of tsunami damage reduced by the coastal levees". Calculate for $1 \mathrm{~m}$ increments of the coastal levee height. The increment of the benefit $\Delta$ Benefit $(K)$ by further increasing the height of the coastal levee $K \mathrm{~m}$ high by $1 \mathrm{~m}$ can be calculated as shown in Eq. (21). For an optimal coastal levee height of $K^{*}$, the increment in the cost exceeds the increment in the benefit when the coastal levee height is further increased by $1 \mathrm{~m}$. Eq. (22) is the optimum conditional equation.

$$
\Delta \operatorname{Benefit}(K)=\sum_{i=1}^{111}\left[D_{i}(K)-D_{i}(K+1)\right]
$$




$$
\begin{aligned}
& \Delta \text { Benefit }\left(K^{*}\right) \geq \Delta \operatorname{Cost}\left(K^{*}\right)\left(\equiv C\left(K^{*}\right)-C\left(K^{*}-1\right)\right) \text { and } \\
& \Delta \operatorname{Benefit}\left(K^{*}+1\right)<\Delta \operatorname{Cost}\left(K^{*}+1\right)\left(\equiv C\left(K^{*}+1\right)-C\left(K^{*}\right)\right)
\end{aligned}
$$

\subsection{Simulation results}

In social optimal case, Table 2 shows the benefit, or the sum of the change in residents' welfare and the change in land owners' income, when coastal levees with a height of $5 \mathrm{~m}$ to $15 \mathrm{~m}$ above T.P. are developed in the Takata area. The benefit and cost are shown as an increase or decrease from the standard (with a coastal levee height of $6 \mathrm{~m}$ ).

Figure 2(b) shows the same as a graph. The benefit is shown by the light blue line whereas the coastal levee improvement cost is shown by the dark blue line. The net benefit obtained by subtracting the improvement cost from the benefit is shown by the red line. If the improved coastal levees exceed the tsunami height of $8 \mathrm{~m}$, the growth of the benefit slows down. This is attributable to the decrease in the frequency of arrival of tsunamis that exceed $8 \mathrm{~m}$ high as shown in Fig. 2(a). The social optimal coastal levee height in Takata area is $10 \mathrm{~m}$ above T.P., where the net benefit is about $¥ 11.4$ billion.

Table 2 Results in the social optimal case (Units: Present value)

\begin{tabular}{|c|l|r|r|r|r|r|r|r|r|r|r|r|}
\hline \multicolumn{2}{|c|}{ Coastal levee height (above T.P.) } & $5 \mathrm{~m}$ & $\begin{array}{c}\mathbf{6 m} \\
\text { (Standard) }\end{array}$ & $7 \mathrm{~m}$ & $8 \mathrm{~m}$ & $9 \mathrm{~m}$ & $10 \mathrm{~m}$ & $11 \mathrm{~m}$ & $12 \mathrm{~m}$ & $13 \mathrm{~m}$ & $14 \mathrm{~m}$ & $15 \mathrm{~m}$ \\
\hline \multirow{3}{*}{ Benefit } & Domestic accounts (in $¥ 100$ million) & -66.1 & $\mathbf{0 . 0}$ & 59.3 & 107.8 & 124.8 & 142.2 & 163.1 & 185.0 & 207.3 & 230.2 & 253.7 \\
\cline { 2 - 13 } & Land owners (in $¥ 100$ million) & -3.1 & $\mathbf{0 . 0}$ & 2.7 & 4.7 & 5.4 & 6.1 & 7.2 & 8.3 & 9.4 & 10.5 & 11.7 \\
\cline { 2 - 27 } & Increase/decrease (in $¥ 100$ million) & -69.2 & $\mathbf{0 . 0}$ & 62.0 & 112.5 & 130.2 & 148.3 & 170.3 & 193.2 & 216.7 & 240.7 & 265.3 \\
\hline Cost & Increase/decrease (in $¥ 100$ million) & -1.8 & $\mathbf{0 . 0}$ & 3.1 & 8.5 & 17.9 & 34.4 & 63.4 & 114.3 & 203.4 & 359.6 & 633.5 \\
\hline \multicolumn{2}{|c|}{ Net benefit (in $¥ 100$ million) } & -67 & $\mathbf{0}$ & 59 & 104 & 112 & 114 & 107 & 79 & 13 & -119 & -368 \\
\hline
\end{tabular}

Note: Increase/decrease means the difference from the standard, where the coastal levee height is $6 \mathrm{~m}$, due to the increase/decrease in the coastal levee height.

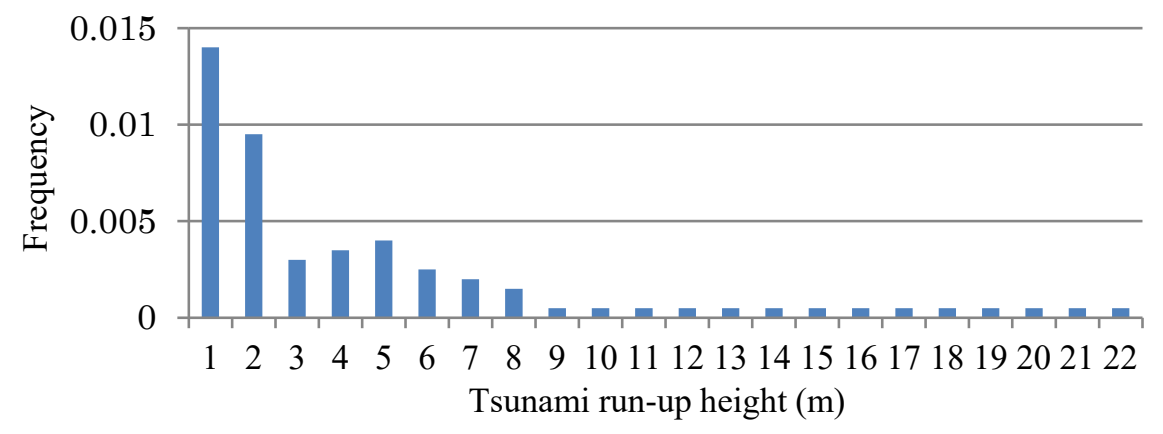


(a) Frequency of tsunami arrival by run-up height per year (estimated)

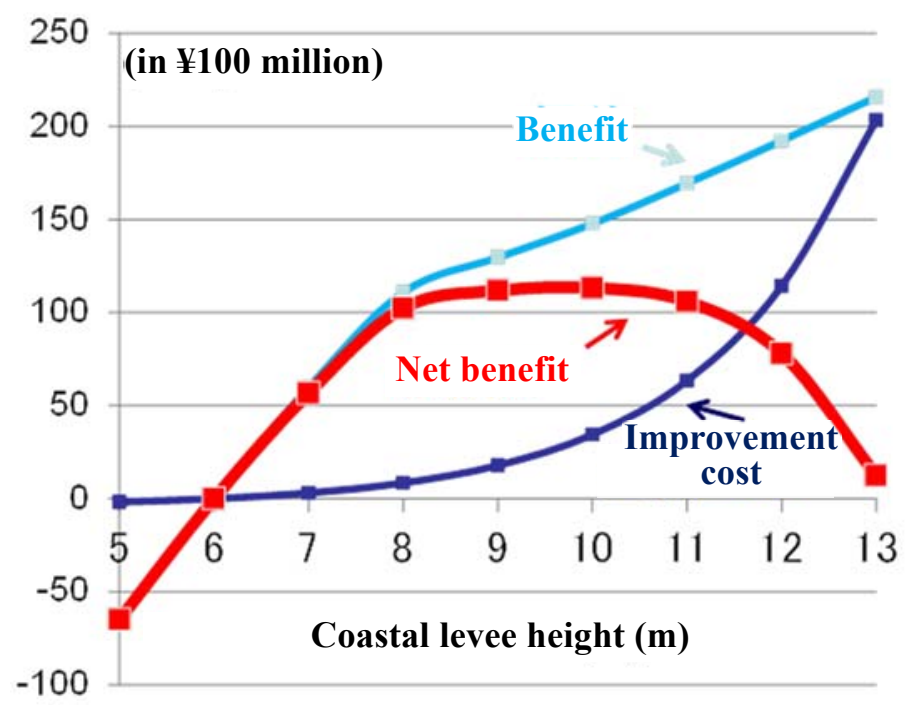

(b) Simulation results in the social optimal case (corresponding to Table 2)

Figure 2 Frequency of tsunami arrival and Simulation results

In Dynamic inconsistency case, the government determines the coastal levee height through CBA after residents have strategically migrated. The optimal coastal levee height for each population obtained through CBA is shown in Table 3 (a). When the population of the Takata area is increased to about 1.5 times $(13,080$ people) from the social optimal ( 8,440 people), the improved coastal levee height was $11 \mathrm{~m}$ above T.P., $1 \mathrm{~m}$ higher than in the social optimal case.

Table 3 Population and coastal levee height

(a) Coastal levee height obtained through CBA with the population as a given condition 


\begin{tabular}{|r|r|r|}
\hline $\begin{array}{c}\text { Given condition: Population of } \\
\text { the Takata area (people) }\end{array}$ & $\begin{array}{c}\text { Optimum coastal levee height } \\
\text { through CBA: T.P. (m) }\end{array}$ & $\begin{array}{c}\text { Results: Amount of damage } \\
\text { reduced (in } ¥ 100 \text { million) }\end{array}$ \\
\hline (Before the Earthquake) 6885 & 9.5 & 128.0 \\
\hline 7575 & 9.5 & 145.0 \\
\hline (Optimal) & 10.0 & 167.9 \\
\hline 8440 & 10.0 & 181.8 \\
\hline 8950 & 10.0 & 189.8 \\
\hline 9640 & 10.0 & 209.8 \\
\hline 10330 & 10.0 & 223.8 \\
\hline 11015 & 10.5 & 251.0 \\
\hline 11705 & 10.5 & 265.8 \\
\hline 12395 & 11.0 & 289.0 \\
\hline 13080 & 11.0 & 313.3 \\
\hline 13770 & & \\
\hline & &
\end{tabular}

(b) Population in equilibrium with the coastal levee height as a given condition

\begin{tabular}{|c|c|}
\hline $\begin{array}{c}\text { Given condition: Coastal } \\
\text { levee height above T.P. (m) }\end{array}$ & $\begin{array}{l}\text { Results: Population in the } \\
\text { Takata area (people) }\end{array}$ \\
\hline 6.0 & (Before the earthquake) 6885 \\
\hline 7.0 & 7600 \\
\hline 8.0 & 8095 \\
\hline 9.0 & 8265 \\
\hline 10.0 & (Optimal) \\
\hline 11.0 & 8645 \\
\hline 12.0 & 8860 \\
\hline
\end{tabular}

\subsection{Discussion}

Here, the above two cases, which are the social optimal case and the dynamic inconsistency case, are compared using Fig. $3 .^{25}$ The vertical axis (A) represents the improved coastal levee height, the vertical axis (B) represents the net benefit to the Takata area, and the horizontal axes for both (A) and (B) represent the population of the Takata area. On the horizontal axis, the minimum value is the population of the Takata area before the earthquake and the maximum value is about twice that.

Curve (a) is the result in the dynamic inconsistency case and shows the improved coastal levees determined through CBA after the population of the Takata area has been determined (as shown in Table 3 (a)). Curve (b) is the result in the social optimal case and shows the population of the Takata area when the population in equilibrium after the coastal levee height has been determined settles (as shown in Table 3 (b)). Curve (c) shows the benefit to the Takata area for each improved coastal levee height following the comparison

25 This figure corresponds roughly to Figure 2 by Kono and Notoya (2012). 
of the amount of damage reduced for each improved coastal levee height with the case of the coastal levee height of $6 \mathrm{~m}$ above T.P. before the earthquake. The difference between (a) and (b) shows the existence of a dynamic inconsistency problem as well as its degree, and curve (c) shows the benefit that causes the dynamic inconsistency.

As curve (c) shows, the benefit continues to increase even if the population exceeds 13,080 shown at the right end of the graph. Hence, if the government improves the coastal levees based on the benefit and cost according to the population scale, further higher coastal levees can be constructed. However, since developers and/or residents cannot continue to mislead the government infinitely, the following discussion limits the population to some large population.

Assuming that the improved coastal levee is $11 \mathrm{~m}$ above T.P. in the case where the population of the Takata area is 1.5 times (i.e., 13,080) the social optimal condition, the difference in cost is about $¥ 2,900$ million compared with the case where improved coastal levees with an social optimal height of $10 \mathrm{~m}$ above T.P. are developed. This means that taxes are injected into a useless public investment. If the difference in cost is converted into a flow value using a social discount rate of $4 \%$, this is equivalent to about $¥ 120$ million. This amount was equivalent to over $1 \%$ of the city's annual budget.

Table 3 (and Fig. 3) clarify that the improved coastal levee height determined through CBA is $11 \mathrm{~m}$ when the population of the Takata area is 13,080 , whereas the population in equilibrium is 8,645 when the improved levee height is $11 \mathrm{~m}$. This means that, the population 13,080 is not an equilibrium population at $11 \mathrm{~m}$ height. In order for the government to project this equilibrium in advance, however, it is necessary to know the residents' preference. Generally speaking, the government cannot know the residents' preference. 


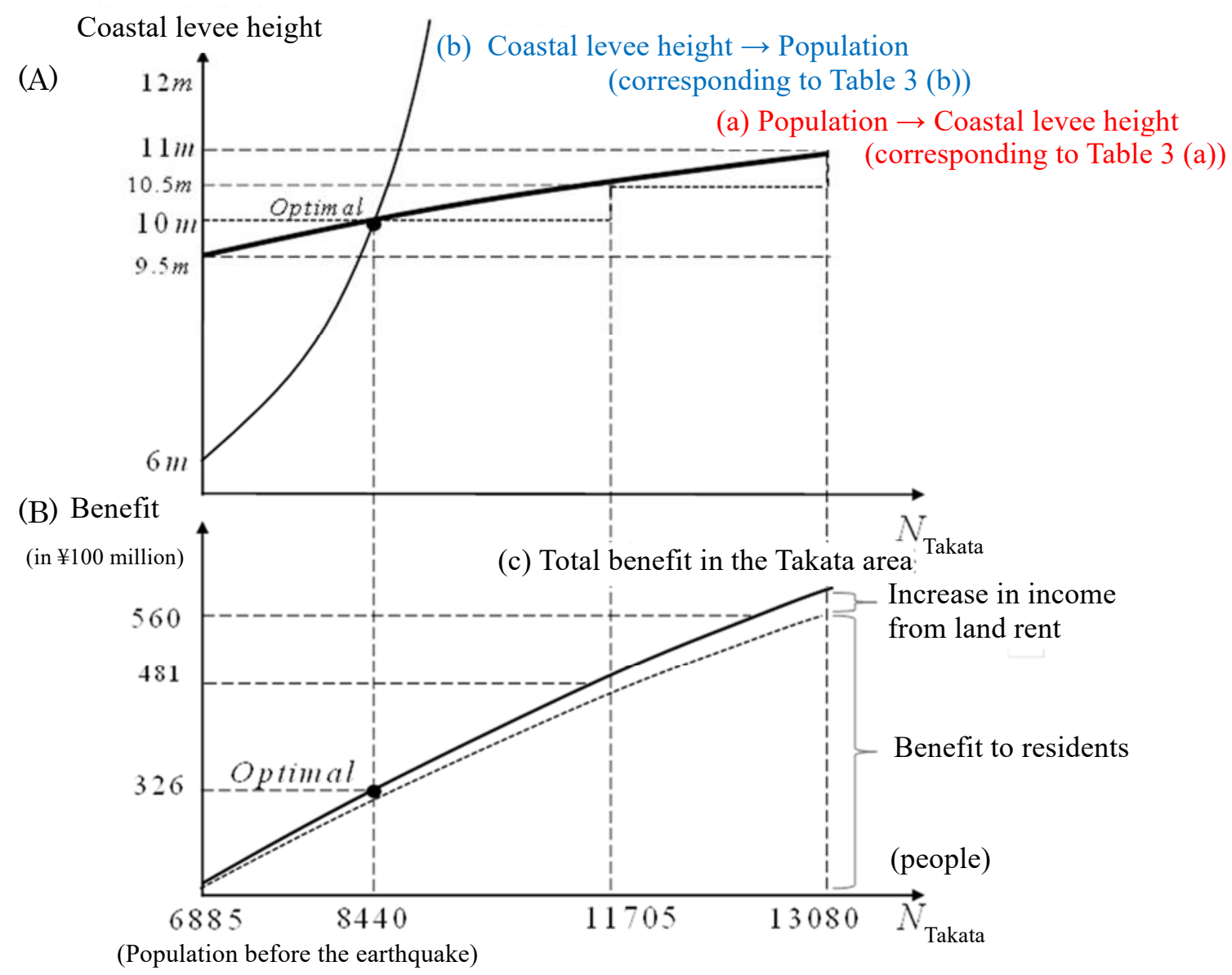

Figure 3 Results of dynamic inconsistency

Finally, the infrastructure improvement cost and the degree of the dynamic inconsistency problem are analyzed to discuss the dynamic inconsistency problem in infrastructure other than coastal levees. As shown by the dark blue line in Fig. 2(b), the coastal levee improvement is considered as an infrastructure improvement with a cost that increases intensively with an increase in scale. Hence, even though many residents have migrated to the Takata area to increase the population to a level of about 1.5 times the optimal population as a result of the strategic behavior of the developers, the coastal levee height has changed from an social optimal height of $10 \mathrm{~m}$ above T.P. only to a height of $11 \mathrm{~m}$ above T.P. However, in the case of an infrastructure improvement where the improvement cost gradually increases with the increase in scale, such as road improvement, the increase 
in the scale of improvement is more sensitive to the strategic behavior using CBA, and the inefficiency of the dynamic inconsistency problem is incurred on a larger scale.

\section{Conclusions}

The degree of inefficiency of the dynamic inconsistency problem in the coastal levee improvement in Rikuzentakata was shown using a calibrated CUE model. If the population of the Takata area were twice what it was before the Great East Japan Earthquake, the coastal levees would be increased to $1 \mathrm{~m}$ higher than the optimal height of $10 \mathrm{~m}$. This additional cost is equivalent to over $1 \%$ of the annual budget of Rikuzentakata.

The cost of the coastal levees increases significantly as the improved height increases. The cost increase is particularly significant when the height exceeds $10 \mathrm{~m}$. Hence, even if many people migrate strategically, the increase in the optimal height is limited to $1 \mathrm{~m}$. However, in the case of infrastructure improvement, such as road improvements, where the cost increases only gradually with an increase in the scale of improvement, the inefficiency that accompanies the dynamic inconsistency problem is eventually incurred on a larger scale. Consequently, careful attention must be paid to the dynamic inconsistency problem particularly concerning projects where the improvement cost increases only gradually ${ }^{27}$.

\section{Appendix.}

This appendix shows the estimated time value, income, land and traffic parameters, and commuting time, together with the respective sources of data used for calibration. The data and other details are shown in Supplement on the authors' website.

Time value $w$ (=wage rate): Weight-average the binding hour per person

27 To avoid the dynamic inconsistency problem in public projects, it is reasonable for the residents, who are the beneficiaries, to bear all of the costs. However, it is generally difficult to establish a system whereby residents bear all of the costs. Since it is also difficult to use various other taxes that can conceivably establish a framework whereby only beneficiaries bear the costs, it will be impossible to completely avoid the beneficiaries getting a free ride. Hence, it is necessary to handle the improvement work taking into account the unavoidable dynamic inconsistency problem. 
(hours/man-day) in the 2000 NHK Japanese Time Use Survey using the population (people) by age group obtained in the 2005 national census and multiply the total population (people) to obtain the total working hours (hours). Subsequently, divide the employees' income (yen) in Prefectural Economic Accounts by the total working hours to determine the time value. Other details are shown in Table 1 (see No. 1 to 5).

Income by age group $I_{i}^{m}$ : Create the data by multiplying the estimated time value (yen/hour) and the value obtained by subtracting the commuting time by zone subsequently created from the binding hour per person (i.e., $I_{i}^{m} \equiv w\left(t^{m}-s_{i}^{m}\right)$ ). (See Nos. 5 and 6 in Table 1.)

Traffic parameter $\alpha_{x}^{m}$ : As shown in Eq. (5), the traffic parameter shows the annual consumption on traffic (yen/year), which is created by multiplying the time value and the number of personal trips per person (trips/person) $\times$ personal trip time per person (hours/trip) $\times 365$ (days) together. (See Nos. 5, 7, 8, and 9 in Table 1.)

Land parameter $\alpha_{l}^{m}$ : As shown in Eq. (5), the land parameter shows the annual consumption on land (yen/year), which is created by multiplying the income by age group by the housing loan to income ratio. (See Nos. 10 and 11 in Table 1.)

Commuting time $s_{i}^{m}$ : The residents commute to work or school. The commuting time is the average time by origin zone, which is created by multiplying the value obtained by weight-averaging the time required to travel between the respective zones with respect to the number of commuting trips at the destination by the number of commuting trips per person (trips/person) (see Nos. 12-16 in Table 1 for the detailed).

Table 1 Data source on Time value, income, traffic and land parameters 


\begin{tabular}{|c|c|c|c|}
\hline No. & Item & Unit & Data source or calculating method \\
\hline 1 & Binding hour per person by age group & $\begin{array}{l}\text { hours/ person- } \\
\text { day }\end{array}$ & $\begin{array}{l}2000 \text { Japanese Time Use Survey (National Version), Weekdays, Total } \\
\text { average time use, The non-elderly, The elderly (Average of those in their 60s } \\
\text { and } 70 \text { s and older) }\end{array}$ \\
\hline 2 & Population by age group & people & 2005 national census \\
\hline 3 & $\begin{array}{l}\text { Total annual working hours by age } \\
\text { group }\end{array}$ & hours/y ear & $\begin{array}{l}\text { 1. Annual working hours per person } \times 2 \text {. Population by age group } \times 365 \\
\text { days }\end{array}$ \\
\hline 4 & Employ ees' income & yen/y ear & Prefectural Economic Accounts, Compensation of Employees \\
\hline 5 & Time value $w$ & yen/hour & 4. Employ ees' income/3. Annual working hours \\
\hline 6 & Income $I=w(t-s)$ & yen/y ear & 5. Time value $w \times(1$. Binding hour $t-$ Commuting time $s)$ \\
\hline 7 & Number of personal trips per person & trip/person & Estimated number of personal trips (seeAppendix 2)/population \\
\hline 8 & Personal trip time per person & hours/person & M inimum expected cost by origin zone \\
\hline 9 & $\alpha^{m}{ }_{x}(=$ Consumption on traffic $)$ & yen/y ear & $\begin{array}{l}365 \text { days } \times 5 \text {. Time value } \times 7 \text {. Number of personal trips per person } \times 8 \text {. } \\
\text { Personal trip time }\end{array}$ \\
\hline 10 & Housing loan to income ratio & $\%$ & $\begin{array}{l}\text { Annual report on family income and expenditure survey, Ratio of the } \\
\text { amount of repayment of loans for house \& land purchases to real income for } \\
\text { households with housing loans (repay ing loans for house \& land purchases) } \\
\text { (Average for all age groups: } 15.5 \%^{*} \text { ) }\end{array}$ \\
\hline 11 & $\alpha^{m}{ }_{l}(=$ Consumption on land $)$ & yen/y ear & 6. Income $\times 10$. Housing loan to income ratio \\
\hline 12 & Commuting time to work per trip & hours/trip & $\begin{array}{l}\text { Weight-average the required time between zones using the trips to work at } \\
\text { the destination. }\end{array}$ \\
\hline 13 & Commuting time to school per trip & hours/trip & $\begin{array}{l}\text { Weight-average the required time between zones using the trips to school at } \\
\text { the destination. }\end{array}$ \\
\hline 14 & Number of trips to work per person & trips/person & Number of trips to work/population \\
\hline 15 & Number of trips to school per person & trips/person & Number of trips to school/population \\
\hline 16 & Commuting time $s$ & hours/p erson & $\begin{array}{l}\text { 1. Commuting time to work } \times 3 \text {. Number of trips to work per person }+2 \text {. } \\
\text { Commuting time to school } \times 4 \text {. Number of trips to school per person }\end{array}$ \\
\hline
\end{tabular}

Based on the data, the time value $w$, traffic and land parameters $\alpha_{x}^{m} \quad \alpha_{l}^{m}$ are calibrated as 538.0, 40.8 and 18.0 for people less than 65 years old, and 538.0, 41.6, and 20.2 for people at 65 years old and more.

\section{Residential land supply function estimation}

The regression analysis is applied to a specified function (8) after taking log forms on both sides. The results are: $\ln A=1.5077$ (1.95), $\sigma=0.53335$ (2.04) and corrected $R^{2}=0.195$, where values in ( ) are t-values. The data used were extracted from the data in the Takata area and the number of the zones used is fourteen.

$\bigcirc$ Coastal levee improvement cost estimation

The data are from p. 205 of the "Report on the Recovery Process from the 1960 Chilean Earthquake Tsunami Disaster" by Iwate Prefecture and the coastal levee improvement cost approximation (12.5m above T.P.) as of 2012. The construction deflator is used to convert the project cost in 1969 into a present value. The regression analysis results for Eq. (19) 
are: $\ln \gamma=-0.34170(-0.86), \phi=0.56136(9.38)$ and Corrected $\mathrm{R}^{2}$-value $=0.916$, where () denotes t-value.

\section{References}

Akai, N. and Sato, M. 2008. "Too big or too small? A synthetic view of the commitment problem of interregional transfers," Journal of Urban Economics 64: 551-559.

Anas, A. 2013. "A summary of the applications to date of RELU-TRAN, a microeconomic urban computable general equilibrium model." Environment and Planning B: Planning and Design 40(6), 959-970.

Anas, A. and Hiramatsu, T. 2012. "The effects of the price of gasoline on the urban economy: From route choice to general equilibrium," Transportation Research Part A 46: $855-873$.

Barro, R. J. and Gordon, D. B. 1983. "A Positive Theory of Monetary Policy in a Natural Rate Model," Journal of Political Economy 91:589-610.

Bassetto, M. 2008. "Political economy of taxation in an overlapping-generations economy," Review of Economic Dynamics 11: 18-43.

Boadway, R., N. Marceau, and M. Marchand. 1996. "Investment in Education and the Time Inconsistency of Redistributive Tax Policy,” Economica 63: 171-189.

Brender, A. and Drazen, A. 2004. "Political Budget Cycles in New Versus Established Democracies,” Journal of Monetary Economics, 52:1271-1295.

Bröcker, J. 1998. “Operational spatial computable general equilibrium models," Annals of Regional Science 32: 367-387.

Cabinet Office, 2007, Research report on economic analysis of damage and loss caused by traffic accidents http://www8.cao.go.jp/koutu/chou-ken/19html/gaiyou.html (Accessed in 2012. 2) (in Japanese)

Calvo, G. A.1978. "On the Time Consistency of Optimal Policy in a Monetary Economy," Econometrica 46: 1411-1428.

Calvo, G. A.1978. "Optimal seigniorage from money creation,” Journal of Monetary Economics 4: 503-517.

Echenique, M. H. 1994. Urban and regional studies at the Martin Centre: its origins, its present, its future. Environment and Planning B 21: 517-517.

Glazer, A. 2000. “Time consistency of congestion tolls," Journal of Transport Economics 
and Policy 34: 301-310.

Iwate Prefecture,1969. "Report on the Recovery Process from the 1960 Chilean Earthquake Tsunami Disaster." Chapter 7, pp. 105-259. (in Japanese)

Iwate Prefecture, 2003. "Earthquake and Tsunami Simulation and Damage Estimation Survey of Iwate Prefecture. Jpg file (Accessed in 2012. 2) http://www.pref.iwate.jp/ hp010801/tsunami/yosokuzu/rikuzentakada.jpg

Kii, M. and Doi, K. 2005. "Multiagent land-use and transport model for the policy evaluation of a compact city." Environment and planning B: Planning and design, 32, 485-504.

Kono, T. and Notoya, H. 2012. "Is Mandatory Project Evaluation Always Appropriate? Dynamic Inconsistencies of Irreversible Projects," Journal of Benefit-Cost Analysis 3: Article 3.

Kornai, J., 1979. "Resource-Constrained versus Demand-Constraint Systems," Econometrica 47: 801-820.

Kydland, F. E. and Prescott, E. C. 1977. "Rules Rather than Discretion: The Inconsistency of Optimal Plans," Journal of Political Economy 85: 473-492.

Ministry of Land, Infrastructure, Transport and Tourism, 2011. Construction Work Cost Deflator. Excel file http://www.e-stat.go.jp/SG1/estat/List.do?lid=000001076277 (Accessed in 2012. 2)

Ministry of Land, Infrastructure, Transport and Tourism, Nationwide Person Trip Survey in 1999. (in Japanese)

Ministry of Land, Infrastructure, Transport and Tourism, Tokyo Metro Area Person Trip Survey in 1998 (in Japanese)

Mitsui, K. and Sato, M. 2001. "Ex ante free mobility, ex post immobility, and time consistency in a federal system," Journal of Public Economics 82: 445-460.

National Oceanic and Atmospheric Administration. National Geographical Data Center: Natural Hazards, Tsunami Runup. (Accessed in 2012. 2)

http://www.ngdc.noaa.gov/nndc/struts/form?t=101650\&s $=167 \& d=166$

NHK Broadcasting Cultural Research Institute (Public Opinion Research Department), 2011. NHK Japanese Time Use Survey Report (pdf file). (Accessed in 2012. 2) (in Japanese)

http://www.nhk.or.jp/bunken/summary/yoron/lifetime/pdf/110223.pdf

Persson, T. and Tabellini, G. 2004. "Constitutional Rules and Fiscal Policy Outcomes," American Economic Review 94: 25-45. 
Pettersson-Lidbom, P. 2010. "Dynamic Commitment and the Soft Budget Constraint: An Empirical Test," American Economic Journal: Economic Policy, 2: 154-179.

Qian, Y. and Roland, G. 1998. "Federalism and the Soft Budget Constraint," American Economic Review 88: 1143-1162.

Richer, J. 1995. "Urban congestion and developer precommitments: Unilateral solutions to dynamic inconsistency," Urban Studies 32: 1279-1291.

Statistic Bureau, Ministry of Internal Affairs and Communications, 2005 National Census

Ueda, T., Tsutsumi, M., Muto, S., and Yamasaki, K. 2012. "Unified computable urban economic model," Annals of Regional Science 50: 341-362.

Yusuke Kiuchi, 2005. "A Literature Survey of Time-Inconsistency Problem in Economic Policy,” Economics, Osaka University 55: 45-63. 